\title{
Changes in physicochemical characteristics, polyphenolics, and amino acids of wax apple cider vinegar during prolonged storage
}

\author{
Somwang Lekjing and Karthikeyan Venkatachalam* \\ Faculty of Innovative Agriculture and Fishery Establishment Project, Prince of Songkla University (Surat Thani Campus), \\ Makham Tia, Muang, Surat Thani 84000, Thailand
}

*Corresponding Author: Karthikeyan Venkatachalam, Faculty of Innovative Agriculture and Fishery Establishment Project, Prince of Songkla University (Surat Thani Campus), Makham Tia, Muang, Surat Thani 84000, Thailand. Email: karthikeyan.v@psu.ac.th; drkarthikeyan.v@outlook.com

Received: 8 April 2021; Accepted: 29 June 2021; Published: 8 July 2021

(c) 2021 Codon Publications

OPEN ACCESS (C)

PAPER

\begin{abstract}
Several quality attributes of wax apple cider vinegar (WACV) were determined every 30 days for six months at ambient temperature. Acetic acid fermentation significantly increased the acetic acid content in WACV. The lightness and yellowness gradually decreased, whereas redness increased during storage. Density, viscosity, and $\mathrm{pH}$ of WACV continuously retarded, and total acidity, volatile acidity, electrical conductivity, and total nitrogen content increased during storage. Phenolic and flavonoid contents and antioxidant potentials of WACV were affected by storage. Various amino acids and volatile compounds were observed in WACV during storage. Throughout the storage period, the microbial growth in WACV was considerably low.
\end{abstract}

Keywords: wax apple cider vinegar, functional properties, storage, quality

\section{Introduction}

Fruit processing plays a significant role in controlling the quality loss of numerous fruits and vegetables and generates various unique products with added economic value. Wax apple is a fruit susceptible to damage from handling, physiological, and physicochemical changes, which adversely influence its quality and value (Techakanon and Sirimuangmoon, 2020; Venkatachalam et al., 2018). They are one of the unique fruits in peninsular Thailand. Their special characteristics include apple-like crispness, watery sweetness, low pungency, and have a bit of roselike aroma. They are available in different colors, from green to dark red. Usually, a vibrant red color indicates readiness for consumption. Wax apple fruit has a different names depending on the region; common names include rose apple, water apple, wax jambus, lianwu, chomphu, and jamalac. Furthermore, wax apple contains lots of phytochemicals that can possess potent antioxidant activities with health benefits. They are consumed mainly as whole fruit or in fresh-cut form. To date, no products or alternatives are developed nor under development on wax apples. This study initiated developing a wax apple cider (WAC). Cider is a fermented alcoholic (1-12\% alcohol by volume (ABV)) beverage produced by a specific cider yeast. Ciders are popular in Western countries, and their consumption is also increasing in southeast Asia (Wood and Anderson, 2006). WAC possesses low acidity and has improved minerals, increased essential amino acids, phytochemicals, and antioxidants (Techakanon and Venkatachalam, 2021).

Typically, alcoholic beverages are highly resistant against spoilage and most pathogenic microorganisms. The cider is slightly unstable because of its rich sugar and low alcohol content, depending on the fruits and preprocessing conditions. Several traditional and modern techniques have already been used in various ciders to improve their 
quality and characteristics. An alternative approach is to proceed to acetic acid fermentation or conversion of cider into cider vinegar (Lea, 1989). Among the various processed foods, cider vinegar could be a new product suitable for small or large-scale production and a valuable extension to Thailand's food industries.

Cider vinegar is a newly developed product with several health benefits and has extensive culinary applications. Typically, vinegar is the result of failed cider fermentation or poor cider storage conditions and are produced by aerobic fermentation with the acetic acid bacteria, wherein ethanol gets converted into acetic acid. The microorganism is a crucial factor for controlling the fermentation and the product's quality and functional properties (Mas et al., 2014). Wax apple cider vinegar (WACV) is obtained by the double fermentation of alcohol and acetic acid. Initially, apple juice is subjected to alcoholic fermentation to produce the required acetic acid (Dabija and Hatnean, 2014). Later, acetic acid fermentation takes place in two steps. In the first step, ethanol is oxidized to acetaldehyde by alcohol dehydrogenase. Then in the second step, acetaldehyde is oxidized to acetic acid by aldehyde dehydrogenase (Raspor and Goranovic, 2008). The reaction is exothermic, thus increasing the temperature in the medium. The acetic acid can be further oxidized to carbon dioxide when the ethanol concentration is limited in the tricarboxylic cycle, an unwanted process in vinegar production (Johnston and Gaas, 2006).

Cider vinegar is an amazingly versatile cooking ingredient. It adds a tangy taste to many drinks and deepens the flavors of various foods. It is important to note that vinegar is a significant ingredient in most condiments. Mayonnaise and tomato ketchup account for more than $10 \%$ of the vinegar production in America. Cider vinegar benefits include many external that include soothing sunburns and insect bites, shiny hair, and dandruff treatment. Cider vinegar has functional therapeutic properties, such as antioxidative, antibacterial activity, promoting recovery from exhaustion, and regulating blood pressure and blood glucose (Johnston and Gaas, 2006; Verzelloni et al., 2007). With increasing interest in the potential health effects of cider vinegar worldwide, there have been many reports confirming the antioxidative activity of various kinds of cider vinegars (Budak et al., 2014). Phenolic compounds play an essential role in vinegar's antioxidative activity (Shimoji et al., 2002; Verzelloni et al., 2007; Zhao et al., 2018). Several fruits, particularly apple, perry, pear, pome, and orange, are used to produce cider and vinegar products (Techakanon and Sirimuangmoon, 2020). However, no prior research is attempted to produce cider vinegar from wax apples. Also, no study about the stability of such products during prolonged storage is available. Therefore, the present study aimed to explore the possibilities of converting the
WAC into WACV and to extensively study the stability of various chemical components, including phenolics, amino acids, volatile compounds, and antioxidant properties in WACV under prolonged storage.

\section{Material and methods}

\section{Materials and reagents}

Fully matured wax apples (Syzygium agueum Alston cv. Taaptimjan) were purchased from a commercial orchard in Surat Thani province, in southern Thailand. The cider yeast strain (Saccharomyces bayanus) was purchased from FERMENTIS (France). Acetobacter estunensis for vinegar production was obtained from Thailand Bioresources Research Center, Thailand. Folin-Ciocalteu reagent, 2,4,6-Tri (2-pyridyl)-s-triazine (TPTZ), 2,2-diphenyl-2-picrylhydrazyl (DPPH), 2,2-azinobis-(3-ethylbenzothiazoline-6-sulfonate (ABTS), ethylene diamine tetraacetic acid (EDTA), trichloroacetic acid (TCA), L-ascorbic acid, chlorogenic acid, gallic acid, caffeic acid, ferulic acid, vanillic acid, catechin, quercetin, cyanidin-3-o-glucoside, cyanidin-3-o-rutinoside, and amino acid standard solution were purchased from Sigma Aldrich (St. Louis, MO, USA). Ethanol, methanol, and acetic acid were purchased of analytical grade from J. T. Baker (Phillipsburg, NJ, USA). Potato dextrose agar and plate count agar were purchased from HiMedia Laboratory (Mumbai, India).

\section{Wax apple juice extraction}

Matured wax apples of uniform size, color, total soluble solids (10-14 $\left.{ }^{\circ} \mathrm{brix}\right)$, and free from any apparent damage or disease were selected for cider production. The procured fruits were taken to the laboratory within eight hours. Fruits were cleaned of dust with tap water and then washed again with distilled water. Later, the fruits were thoroughly juiced using a food processor in a cold environment, roughly strained and fermented to produce cider.

\section{Cider and cider vinegar preparation}

Wax apple juice $(6 \mathrm{~L})$ was fermented to cider in a fermenter by previously followed method (Venkatachalam et al., 2018). Filtered cider samples proceeded to vinegar production. The cider $(4.7 \%$ alcohol) sample $(10 \mathrm{~L})$ was transferred to a sterile fermenter and inoculated with bacterial culture, specifically Acetobacter estunensis, in a ratio of 10:1. The fermenter was placed in the dark at ambient temperature and was continuously aerated by an electric aeration pump. The acidification was continued 
for 30 days. Every 24 hours, samples were collected and tested for acetic acid content and fermentation efficiency (Figure 1). After fermentation, cider vinegar was filtered to get rid of the slime. Then, the filtered samples were racked in brown bottles for 6 months to study their stability under ambient storage conditions. Every month, samples were measured for various quality criteria.

\section{Quality Analysis}

\section{Physicochemical analysis}

The color coordinates lightness $\left(\mathrm{L}^{*}\right)$, redness $\left(\mathrm{a}^{*}\right)$, and yellowness $\left(b^{*}\right)$ were measured for WAC using a HunterLab Colorimeter. Electrical conductivity was measured using an electrical conductivity meter, and the results were expressed in $\mathrm{mS} / \mathrm{cm}^{2}$. The vinegar sample's density was measured using a hydrometer, and the results were expressed in $\mathrm{g} / \mathrm{cm}^{3}$. The sample's viscosity was analyzed using a Brookfield viscometer, and the results were expressed in $\mathrm{cP}$. The $\mathrm{pH}$ of the cider vinegar was measured using a $\mathrm{pH}$ meter. The fermentation efficiency of cider vinegar during fermentation was measured following the method of Kaur et al. (2011). The results are expressed as percentages. The total nitrogen content in cider vinegar was determined by the Kjeldahl method following AOAC (2000). The results are expressed in g/L. The ethanolic and acetic acid contents in cider before acetic acid fermentation and during the fermentation were analyzed using the chromatographic method proposed by Dias et al. (2016). The results are expressed as percentages. The cider vinegar's total acidity and volatile acidity were measured using the method of Kaur et al. (2011). The results are expressed as percentages.

\section{Phytochemicals, phenolic compounds, and antioxidant activities}

\section{Phytochemical analysis}

For total phenolic content (Alberti et al., 2014), 100 $\mu \mathrm{L}$ of WACV, 8.4 mL of distilled water, and $500 \mu \mathrm{L}$ of Folin-Ciocalteu reagent were added to a test tube. Later, $1 \mathrm{~mL}$ of sodium carbonate (20\%) was added and mixed well. Then, the reaction mixture was incubated at room temperature for 30 minutes and was measured using a spectrophotometer at $720 \mathrm{~nm}$. The absorbance was compared with the calibration curve made using gallic acid $\left(10-100 \mu \mathrm{g} / \mathrm{mL}\right.$; the coefficient of determination $\left(\mathrm{R}^{2}\right)=$ $0.9970 ; \mathrm{P}<0.0001)$. The results were expressed as $\mu \mathrm{g}$ gallic acid equivalent (GAE)/mL. For total flavonoid content (Alberti et al., 2014), $250 \mu \mathrm{L}$ of WACV was placed in the test tube, and $2.72 \mathrm{~mL}$ of $30 \%$ ethanol and $120 \mu \mathrm{L}$ of $0.5 \mathrm{~mol} / \mathrm{L}$ sodium nitrite were added, mixed, and incubated for 5 minutes. Later, $120 \mu \mathrm{L}$ of $0.3 \mathrm{~mol} / \mathrm{L}$ aluminum chloride was added to the mixture, followed by $800 \mu \mathrm{L}$ of $1 \mathrm{~mol} / \mathrm{L}$ sodium hydroxide, and mixed well. Then the reaction mixture was measured at $510 \mathrm{~nm}$ using a spectrophotometer. The absorbance was compared with the calibration curve made using catechin $(10-100 \mu \mathrm{g} / \mathrm{mL}$; $\left.\mathrm{R}^{2}=0.9960 ; \mathrm{P}<0.0001\right)$. The results were expressed as $\mu$ g catechin equivalent $(\mathrm{CE}) / \mathrm{mL}$. For ascorbic acid (AsA; Bavisetty and Venkatachalam, 2021), $1 \mathrm{~mL}$ of WACV and $24 \mathrm{~mL}$ of $0.4 \%$ oxalic acid were mixed in a flask. After that, the reaction mixture was titrated against the $0.04 \%$ aqueous sodium dichlorophenolindophenol solution to obtain the first pink shade (endpoint). Then, the ascorbic acid in WACV was calculated based on the method of Kabasakalis et al. (2000). The results were expressed as $\mu \mathrm{g}$ AsA/ mL.

\section{Phenolic compound analysis}

A sample of WACV (2 mL) was mixed with $4 \mathrm{~mL}$ of $100 \%$ methanol and vortexed at high speed for 1 minute, incubated at $60^{\circ} \mathrm{C}$ for 15 minutes, and was centrifuged at $8160 \mathrm{~g}$ for 20 minutes at an ambient temperature. Later, the supernatant was collected and filtered through a $0.22 \mu \mathrm{m}$ nylon syringe filter (Waters, Milford, MA, USA). High-performance liquid chromatography (HPLC) was performed with the collected filtrate to analyze the phenolics (Alberti et al., 2014). The phenolic compounds mainly gallic acid, chlorogenic acid, caffeic acid, ferulic acid, vanillic acid, cyanidin-3-o-glucoside, and cyanidin3-o-rutinoside; and the flavonols such as catechin and quercetin were identified and quantified in the WACV samples. The standard calibration samples for the listed phenolic compounds in this study were prepared at seven concentrations $\left(10-70 \mu \mathrm{g} / \mathrm{mL} ; \mathrm{R}^{2} \geq 0.998 ; \mathrm{P}<0.0001\right)$. The retention time and ultraviolet spectra of the standards were used to identify and quantify the phenolic compounds in the samples. The results were expressed in $\mu \mathrm{g} / \mathrm{mL}$.

\section{Antioxidant activities}

For DPPH radical scavenging assay (Brand-Williams et al., 1995), $100 \mu \mathrm{L}$ of WACV and $3.9 \mathrm{~mL}$ of $60 \mu \mathrm{mol} / \mathrm{L}$ DPPH were mixed well in a test tube, the reaction mixture was incubated for $30 \mathrm{~min}$ in the dark at an ambient temperature and was measured at $515 \mathrm{~nm}$ using a spectrophotometer. The results were expressed as a percentage of DPPH radical scavenging ability.

For ABTS radical cation scavenging assay, $100 \mu \mathrm{L}$ of WACV and $100 \mu \mathrm{L}$ ABTS reagent (as described in Lee et al., 2015) in a 96 well microplate incubated for 6 minutes at room temperature. Later, the sample was measured at $734 \mathrm{~nm}$ using a microplate reader. The results were expressed as a percentage of ABTS radical scavenging ability.

For ferric reducing antioxidant potential assay (FRAP), $100 \mu \mathrm{L}$ of WACV was mixed with $3 \mathrm{~mL}$ of FRAP reagent 
(as described in Alberti et al., 2014). The reaction mixture was incubated for 20 minutes for a blue-colored complex development and was measured at $593 \mathrm{~nm}$ using a spectrophotometer. The absorbance of sample was compared with the calibration curve made for ferrous ion $\left(\mathrm{Fe}^{2+} ; 10-\right.$ $\left.100 \mathrm{mmol} / \mathrm{mL} ; \mathrm{R}^{2}=0.0997 ; \mathrm{P}<0.0001\right)$. The results were recorded in $\mathrm{mmol} \mathrm{Fe}^{2+}$ equivalent $\left(\mathrm{Fe}^{2+} \mathrm{E}\right) / \mathrm{mL}$.

For hydroxyl radical scavenging assay (Halliwell et al., 1987), $1 \mathrm{~mL}$ of WACV was added to a test tube containing $1 \mathrm{~mL}$ of ferrous ammonium sulfate $(0.13 \%-0.26 \%)$ (EDTA), $0.5 \mathrm{~mL}$ of $0.018 \%$ EDTA, $1 \mathrm{~mL}$ of $0.85 \%$ dimethyl sulfoxide, and $0.22 \%$ ascorbic acid, mixed well, and incubated in a water bath at $90^{\circ} \mathrm{C}$ for $10 \mathrm{~min}$. Later, $1 \mathrm{~mL}$ of ice-cold and $3 \mathrm{~mL}$ of Nash reagent wax were added to the reaction mixture and incubated at room temperature for 15 minutes for yellow color development. Finally, the reaction mixture was measured at $412 \mathrm{~nm}$ using a spectrophotometer, and the outcomes were expressed as a percentage of hydroxyl radical scavenging ability.

\section{Amino acid profile}

About $3 \mathrm{~mL}$ sample of WACV was mixed well with $2 \mathrm{~mL}$ of $0.25 \mathrm{mmol} / \mathrm{L}$ norleucine and centrifuged at 13,000 $\mathrm{g}$ for 20 minutes at $4^{\circ} \mathrm{C}$. The supernatant was collected and filtered through a nylon syringe filter $(0.2 \mu \mathrm{m}$, Waters $)$ and was used to identify the amino acids by the chromatographic method proposed by Alberti et al. (2016). The amino acids were derivatized using a Waters AccQ $\mathrm{Tag}^{\mathrm{Tm}}$ reagent kit (flask 1: $200 \mathrm{mmol} / \mathrm{L}$ borate buffer, $\mathrm{pH}$ 8.8; flask 2A: 6-aminoquinolyl-N-hydroxysuccinimidyl carbamate; and flask 2B: acetonitrile). Then the identification and quantification were accomplished by HPLC using the AccQ Tag reagent kit methodology with a PicoTag column $(4 \mathrm{~mm}, 3.9 \times 150 \mathrm{~mm})$. The identified amino acids in WACV were quantified and were reported in $\mathrm{mg} / 100 \mathrm{~mL}$.

\section{Analysis of volatile compounds}

The volatile compounds in the WACV were extracted and analyzed by gas chromatography-mass spectroscopy (GC-MS; Agilent GC: 6890, with a 7683B autosampler, Agilent Technologies, Palo Alto, CA) using the static headspace method proposed by Pietrowski et al. (2012) with some modifications. The capillary column (Phenomenex column with $30 \mathrm{~m}$ in length with $25 \mathrm{~mm}$ internal diameter and $0.25 \mu \mathrm{m}$ thick ZBWAX film) was attached directly to the Agilent GC. The analysis conditions were programmed with an initial temperature of $40^{\circ} \mathrm{C}$ for 5 minutes and then increased to $10^{\circ} \mathrm{C} / \mathrm{min}$ to $300^{\circ} \mathrm{C}$ with an isothermal state of 10 minutes. The sample injector port temperature was set to $250^{\circ} \mathrm{C}$; the transfer line was set to $290^{\circ} \mathrm{C}$, splitless. About $1.5 \mathrm{~mL}$ sample was injected into $\mathrm{GC}$ via an automatic injector with a column flow rate of $1 \mathrm{~mL} / \mathrm{min}$. LECO Pegasus 4D mass spectrophotometer was used to record the electronic ionization source at $-70 \mathrm{eV}$. The solvent delay was set to 9 minutes, acquisition rate to 10 spectra/second, the ion source temperature to $250^{\circ} \mathrm{C}$, the mass range was 50-1000 amu, detector voltage $1800 \mathrm{~V}$, and the scan time was 1.5 seconds. The data was recorded in total ion chromatogram mode. The Agilent ChemStation software was adopted to Identify the volatile compound name, chemical formula, and \% peak area of unknown compounds and were compared with the known data from the GC-MS library (NIST mass spectral library).

\section{Microbial analysis}

WACV was examined each week for microbiological counts. Plate count agar (PCA) determined the total counts for aerobic microbes. Triplicate serial dilution in peptone water of each sample bag was prepared, $1 \mathrm{~mL}$ from each dilution were aseptically inoculated on a Petri dish with $20 \mathrm{~mL}$ of sterilized agar and mixed thoroughly. Upon agar solidification, the Petri dishes were inverted and incubated for $48 \mathrm{~h}$ at $30^{\circ} \mathrm{C}$. Colonies were counted and are reported as $\log 10 \mathrm{CFU} / \mathrm{mL}$ (American Public Health Association, 1978).

Yeast and mold counts were determined using acidified $(\mathrm{pH} 3.5)$ potato dextrose agar. Dilutions and samples were prepared as described in the PCA method. The sterilized agar's $\mathrm{pH}$ was adjusted to 3.5 , with sterilized $10 \%$ $(\mathrm{W} / \mathrm{V})$ tartaric acid and poured on Petri dishes, mixed thoroughly, inverted, and incubated for two days at $30^{\circ} \mathrm{C}$. Later, colonies were counted and reported as log10 CFU/ $\mathrm{mL}$ (Beever and Bollard, 1970). Escherichia coli (E. coli) was determined using Petrifilm E. coli Count Plate. Onto the center of the bottom film, $1 \mathrm{~mL}$ of sample was added by lifting the top film and was slowly rolled down onto the sample to prevent air bubble entrapment. The plate was left undisturbed for one minute to permit solidification of the gel and then incubated at $37^{\circ} \mathrm{C}$ for two days. After incubation, the colonies were counted and reported as $\log 10 \mathrm{CFU} / \mathrm{mL}$ (AOAC, 2002).

\section{Statistical analysis}

All the experiments were carried out in triplicates. The data were presented as the mean and standard error of the mean (SEM), one-way analysis of variance studied the differences during the storage. Duncan's multiple range test identified the significant differences between the means at $\mathrm{P}<0.05$. SPSS v6 for Windows (SPSS, Chicago, IL, USA) was used to run all the statistical analyses. 


\section{Results and discussion}

\section{Acetic acid production and fermentation efficiency}

WAC was studied for acetic acid production to understand the acetic acid bacteria's efficiency and the cider medium's suitability for acetic acid production for up to 29 days (Figure 1). The fermentation was ceased at 29 days, as no significant changes in acetic acid levels were noted after 20 days. During the continuous acetic acid fermentation of WAC, a gradual increase in acetic acid content was noted. In the initial stages, a gradual increase in the production was recorded on day 11 of the fermentation, an increase in the pace of acetic acid production was noted until day 21. Later it was found to be almost constant till day 29.

Concerning acetic acid production, the ethanol content in WAC gradually decreased during the formation of acetic acid in the WAC. A similar finding was reported by Štornik et al. (2016) in a study of apple cider vinegar production. Kocher et al. (2006) reported that the rapid conversion of ethanol into acetic acid by acetic acid bacteria is facilitated by aeration, stirring, and heating. At the end of the fermentation and before bottling for storage and/or maturation for six months, WACV had about $2.3 \%$ acetic acid. On the other hand, the ethanol content decreased from $4.8 \%$ to $2.1 \%$ as it was used up by the bacteria to produce acetic acid during the fermentation.

The fermentation efficiency (FE) tended to increase with fermentation time (Figure 1). Though a continuous boost in FE was observed during the fermentation, the level of acetic acid was stable after 21 days because of the nature of the acetic acid-producing bacteria. Joshi et al. (2016) reported that some acetic acid-producing bacterial strains could over-oxidize acetic acid into carbon-di-oxide and water, which could halt the acetic acid production in the WAC during the fermentation. Moruno et al. (1993) reported three main factors that could adversely affect the production of acetic acid during fermentation: (1) the genetics of the yeast strain, (2) the presence of polyphenols, especially catechin and anthocyanins, and (3) the presence of unsaturated fatty acids.

\section{Physicochemical properties}

WACV was bright yellowish. During the vinegar-making process, the usual pinkish-yellow WAC wholly turned yellow (Figure 2A). Furthermore, the color changes were consistent during the prolonged storage of WACV (the yellowness increased during storage). On the other hand, the lightness representing luminosity and redness, with negative values representing the darkness, tended to decrease throughout the storage period without many fluctuations in the results. The vinegar samples' color changes could be caused by maturation, with the degradation of anthocyanin residues in WACV and potential effects from acidification. Mas et al. (2014) reported that polyphenolic compounds are responsible for the color and astringency of vinegar. Tarazona-Diaz and Aguayo (2013) observed the reduced redness in the fruit juice during acidification, which agreed with the present study as the $\mathrm{pH}$ of WACV increased during storage (Figure $2 \mathrm{C}$ ). The density decreased steadily, along with viscosity

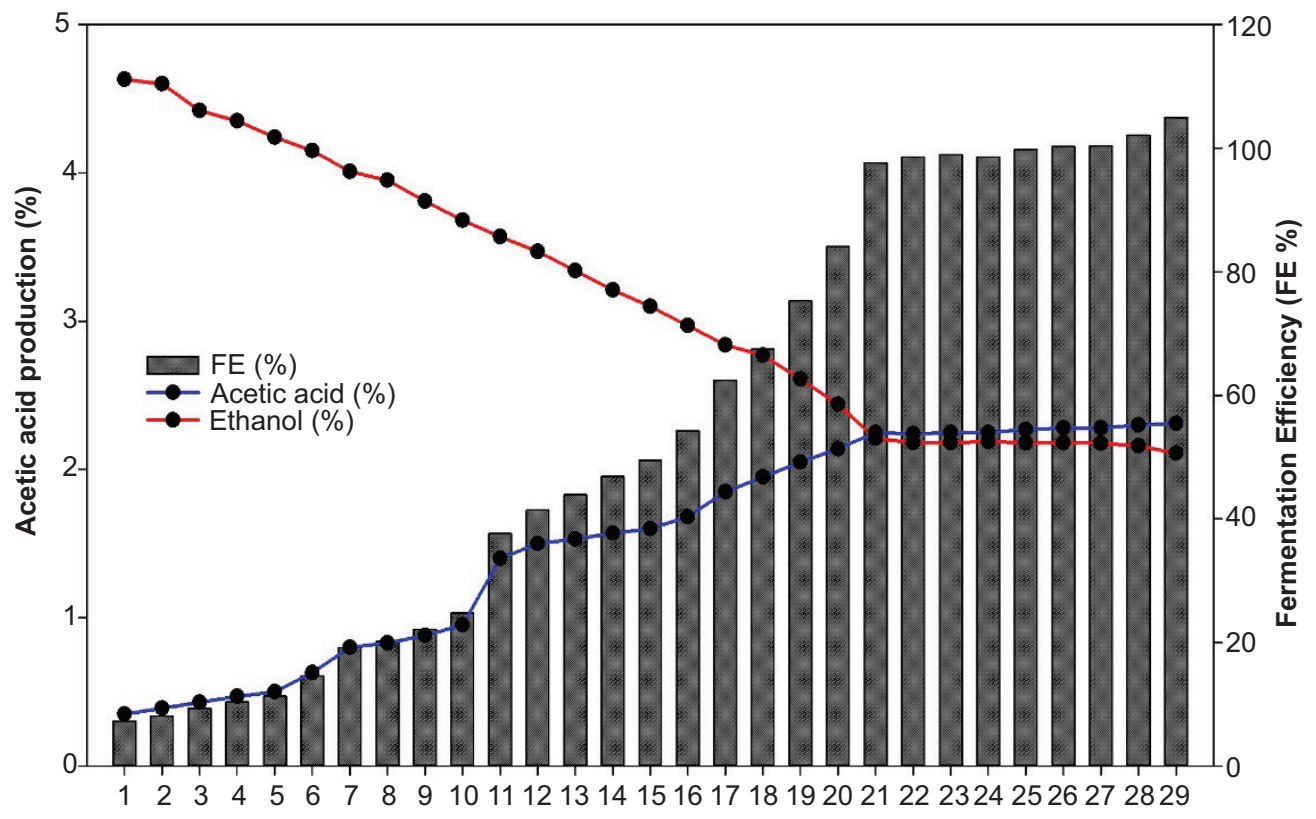

Figure 1. Acetic acid production and fermentation efficiency of wax apple cider. 
(A)

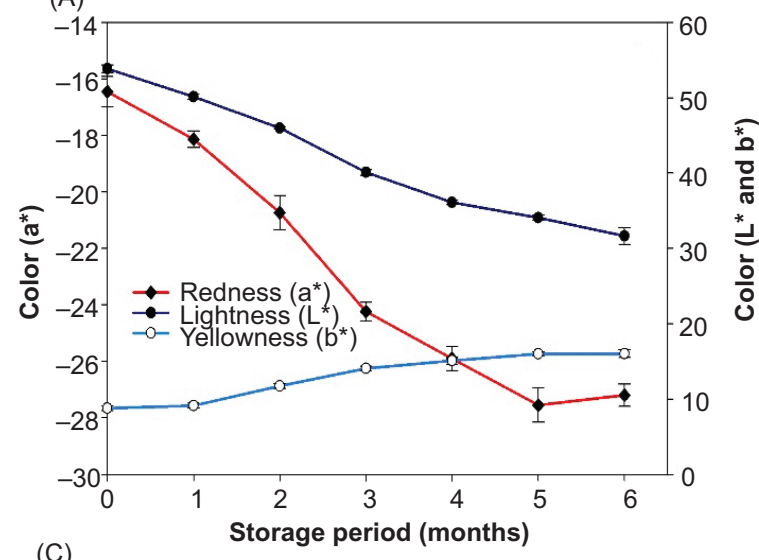

(C)

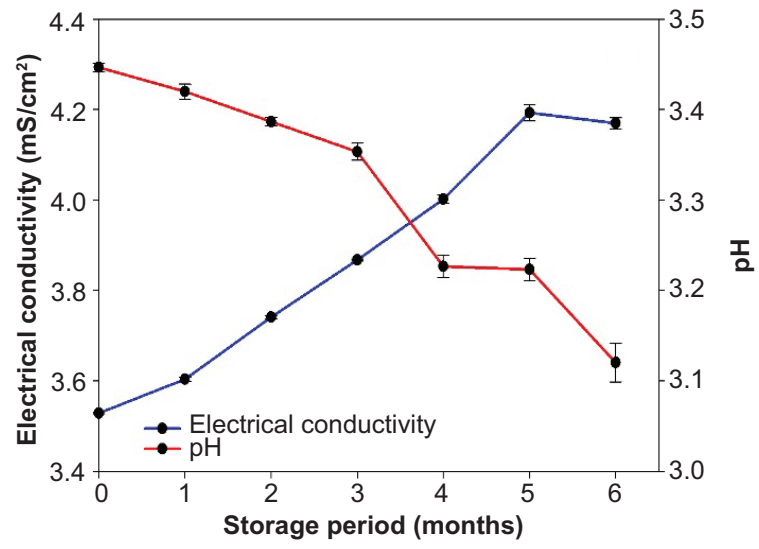

(B)
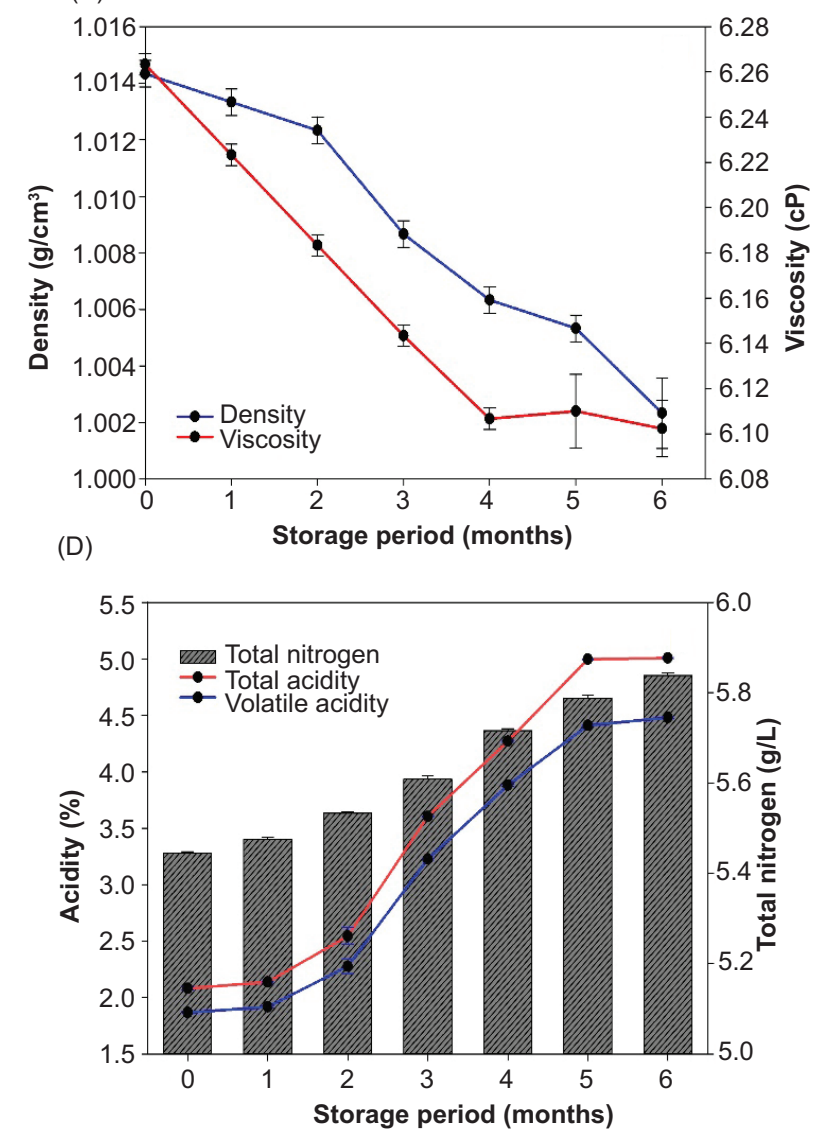

Figure 2. Physiochemical qualities of wax apple cider vinegar during the storage period.

throughout the storage of WACV (Figure 2B). The vinegar density is linked to acetic acid density directly in case it has been distilled.

The present study shows that density decreased with storage time, indicating that organic and inorganic substances in WACV could lose their binding potential and sediment at the bottom of the bottle, consequently affecting density and viscosity. The electrical conductivity of WACV (Figure 2C) shows a linear pattern with storage time. During the study period, it increased from 3.58 to $4.11 \mathrm{mS} / \mathrm{cm}^{2}$. At the end of the study, the conductivity of the samples was slightly lowered. The pH of WACV steadily changed to acidic during prolonged storage under ambient temperature (Figure $2 \mathrm{C}$ ). The $\mathrm{pH}$ was acidic from the beginning (3.44) and gradually decreased to 3.22 at the end of storage. A decrease in $\mathrm{pH}$ is the direct influence of organic acid's presence in the samples. In this study, a continuous increase of acid content (total acidity and volatile acidity) in WACV during the storage was observed (Figure 2D), which agreed with the study of Vithlani and Patel (2010). Although there is a significant change in the $\mathrm{pH}$ and organic acid level in the WACV, it still stayed in the cider vinegar range recommended by the codex (Ho et al., 2017). The total acidity was slightly higher in WACV than in volatile acidity. The increased acidity and decreased $\mathrm{pH}$ in the samples indicate that prolonged storage tended to increase the acidification of WACV. Typically, the volatile acidity represents the odorous fatty acids in vinegar, mainly acetic acid. Chidi et al. (2018) and Jackson (2008) reported that the acetic acid level in vinegar increase during aging. Furthermore, the total nitrogen content in the WACV showed a steady increase during storage (Figure 2D).

\section{Phenolic contents and antioxidant activities}

Phytochemicals of WACV are shown in Figure 3(A). Among the various phytochemicals in the WACV, the total phenolic content (TPC) was the most abundant, followed by total flavonoids (TFC) and AsA. Prolonged storage significantly affected the phytochemicals in the samples. TPC and TFC contents steadily increased in WACV during prolonged storage, whereas AsA steadily decreased. Various phenolic acids and flavonoids in WACV were quantified, and the results are presented in Figure 3(B). Phenolic acids such as gallic 
(A)
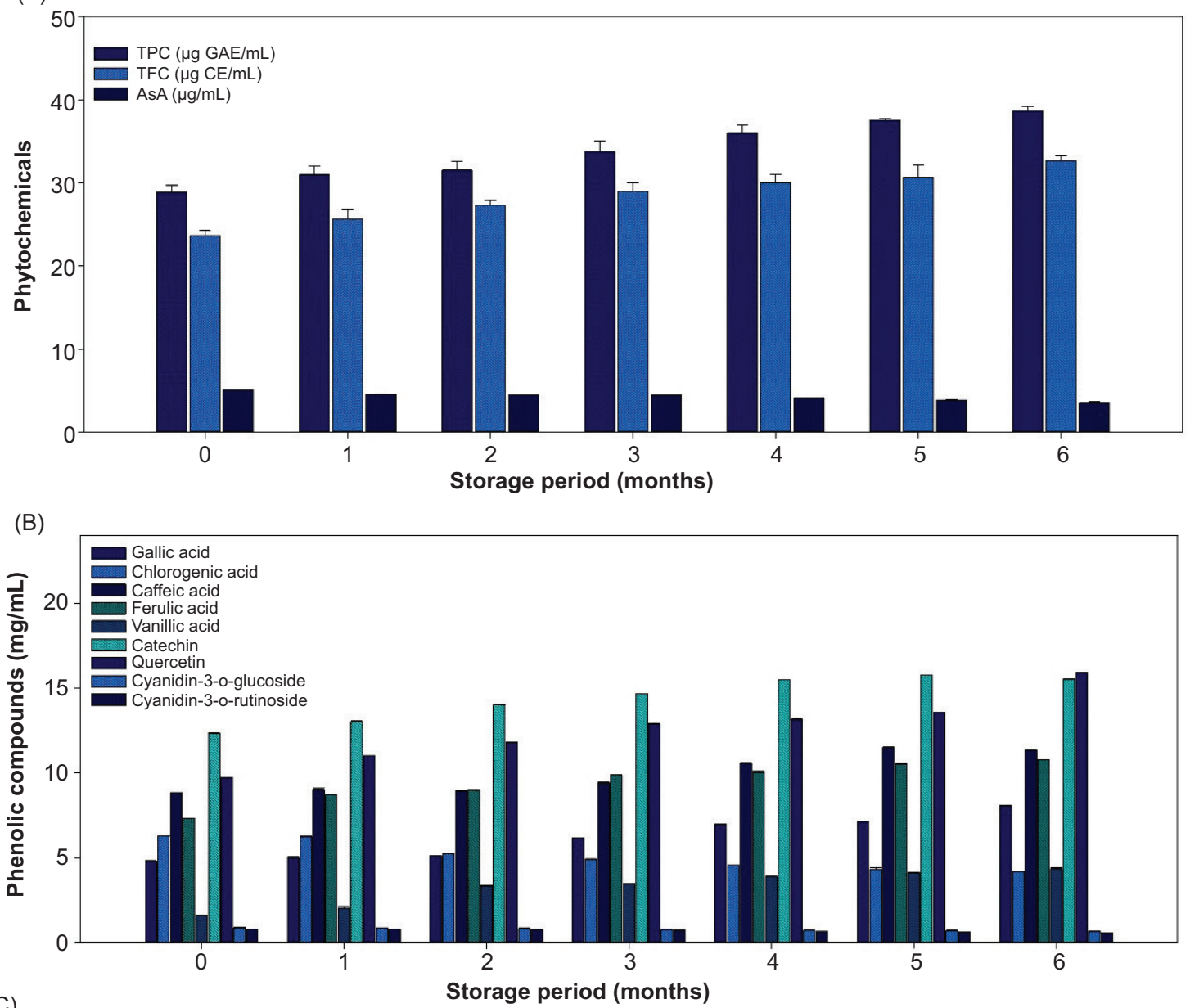

(C)

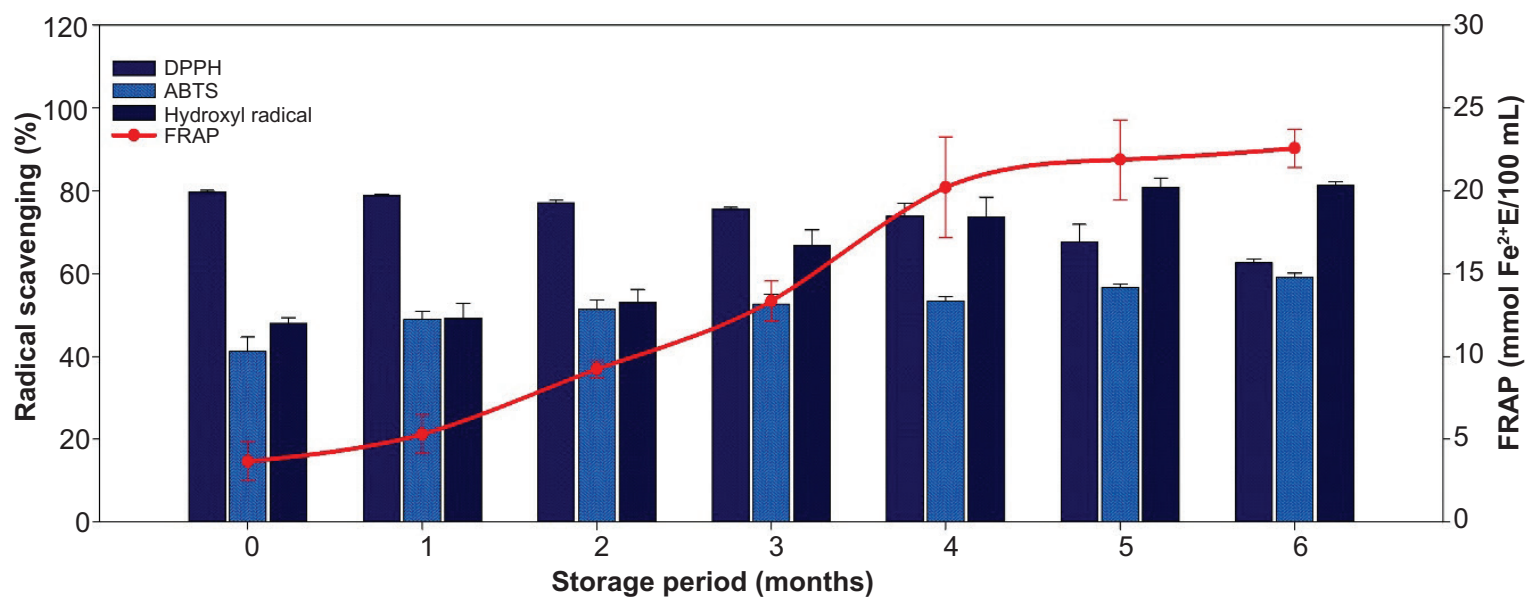

Figure 3. Phytochemicals, phenolic compounds, and antioxidant activities of wax apple cider vinegar during the storage period.

acid, chlorogenic acid, caffeic acid, ferulic acid, and vanillic acid were observed in WACV. Among the various phenolics, caffeic acid, ferulic acid, and gallic acid were the highest in WACV $(\mathrm{P}<0.05)$. Chlorogenic acid tended to decrease throughout the storage period. Vanillic acid gradually increased in WACV until four months and was constant later. However, flavonoids such as catechin and quercetin concentrations highest among the various phenolic compounds. During storage, catechin and quercetin steadily increased in WACA, whereas the lesser components cyanidin-3-o-glucoside and cyanidin-3-o-rutinosidecontinuously decreased. 
Hornedo-Ortega et al. (2017) found that anthocyanin content in the vinegar was more susceptible than in the cider.

Anthocyanin (91\%) continuously decreased in the acetic acid fermentation versus alcoholic fermentation (19\%). Figure $3(\mathrm{C})$ presents the radical scavenging activity of WACV during the prolonged storage period. Among the various scavenging activities, DPPH activity in WACV was higher at the beginning of the storage. For the first four months of storage, minimal changes in the scavenging activity of WACV was noted. When the storage reached between 5 and 6 months, the DPPH activity significantly decreased. Instead, hydroxyl and ABTS radical scavenging activities gradually increased throughout the storage. WACV showed a higher potential of scavenging hydroxyl radicals than ABTS radicals. Davies et al. (2017) have found that the AsA content was the primary contributor of the DPPH activity in vinegar. A reduction of AsA in the vinegar during storage was probably the cause of chemical changes by the bio-oxidative process. Furthermore, the ABTS activity in the vinegar could be influenced by the synergic effect of phenolics, ascorbic acids, and some amino acids (Campodonico et al., 1998). Overall, all types of radical scavenging activities tested in WACV were maintained for at least $40 \%$ of the initial level during the storage. However, the FRAP of WACV was minimal and steadily increased throughout the storage $(\mathrm{P}<0.05)$. FRAP activity is strongly correlated with the polyphenolics present in a food product, especially in beverages, which agreed with the finding of Schlesier et al. (2002).

\section{Amino acid profile}

Table 1 shows the amino acid content in WACV during the prolonged storage period. About 18 amino acids were observed in WACV during storage. The storage period significantly affected the levels of amino acids in WACV. Glutamic acid, hydroxyproline, histidine, lysine, methionine, proline, serine, threonine, tyrosine, valine, and glutamine levels increased in WACV during the storage. However, alanine, arginine, aspartic acid, glycine, isoleucine, leucine, and phenylalanine levels decreased. Alanine, histidine, isoleucine, leucine, and valine were found in very minimal contents in WACV. Acetic acid bacteria could metabolize the amino acids from cider vinegar, particularly alanine, arginine, glycine, and leucine (Valero et al., 2005; Wang et al., 2015). The storage period could limit the suitable conditions for the bacteria to survive and reproduce. Hence, it catalyzed the available resources from the vinegar to sustain. Arginine, lysine, methionine, proline, threonine, and glutamine were the primary amino acids found in the WACV. The other listed amino acids in Table 1 were found at moderate levels. In our previous study (Venkatachalam et al., 2018), we observed 23 amino acids in the WAC.

The present study shows that acetic acid fermentation significantly influenced the amino acid contents. Cysteine, hydroxylysine, tryptophan, asparagine, and glutamine, were not detected in the WACV. Furthermore, Ardö (2006) reported that the aminotransferase enzyme in vinegar could catabolize amino acids (aspartic acid, isoleucine, leucine, and phenylalanine) for flavor formation (buttery, malty, fruity, sweaty, floral, chemical, and fecal).

\section{Volatile profile}

The volatile profile of WACV during prolonged storage is presented in Table 2. Normally, volatile compounds of fermented beverages are by-products of the catabolic processing of amino acids by microorganisms. The volatile profile of WACV was significantly influenced by acetic acid fermentation and by prolonged storage. About 31 volatile flavor compounds were observed in WACV. The present study showed that cider vinegar exhibited complex flavors, including strawberry, apple, raspberry, vinegar, acetic acid, fruity, wine, plastic, sweet, floral, acidic, feet, gruyere cheese, fusty, ripened cheese, rancid, rose, sour, spicy, potato, burnt, floral, honey, wax, caramel, and clover, that agreed with the research of Charles et al., 2000. Most volatile compounds in WACV gradually decreased with storage time. Among the different volatile compounds, acid, and fatty acid-related volatile compounds were predominant, followed by esters, ketones, alkanes, phenol, and benzothiazole. Ethyl acetate and acetoin were the major volatile compounds found in the WACV, which agreed on the studies of Ubeda et al. (2011) and Valero et al. (2005) reporting that acetoin is the predominant volatile compound present in cider vinegar and tends to decrease as the vinegar ages. The other volatiles were minimal.

Volatiles that increased during storage included boranemethyl sulfide, ethyl acetate, 2, 3-butanedione, isoamyl alcohol, 3-acetoxy-2-butanone, dimethyl sulfone, butanoic acid, 2-propenoic acid, benzyl alcohol, 2-ethyl hexanoic acid, benzothiazole, phenol, 2-ethyl heptanoic acid, octanoic acid, nonanoic acid, and decanoic acid. However, 2,4,5-trimethyl-1,3-dioxolane, acetoin, 2-hydroxyethyl propanoate, 1-phenylpropane-1,2-dione, propanoic acid, 3-methyl butanoic acid, $\beta$-phenethyl acetate, hexanoic acid, 2-isopropyl-2,3-dimethylbutanoic acid, 2-ethyl-2,5-dimethylhexanoic acid, (+)-curdione and 4-ethyl-phenol decreased in WACV during the storage. Furthermore, during the storage study, some volatile compounds such as (3,4-diphenylisothiazol-5yl)-phenylmethanone and 2-methylpropylmethyl ether 


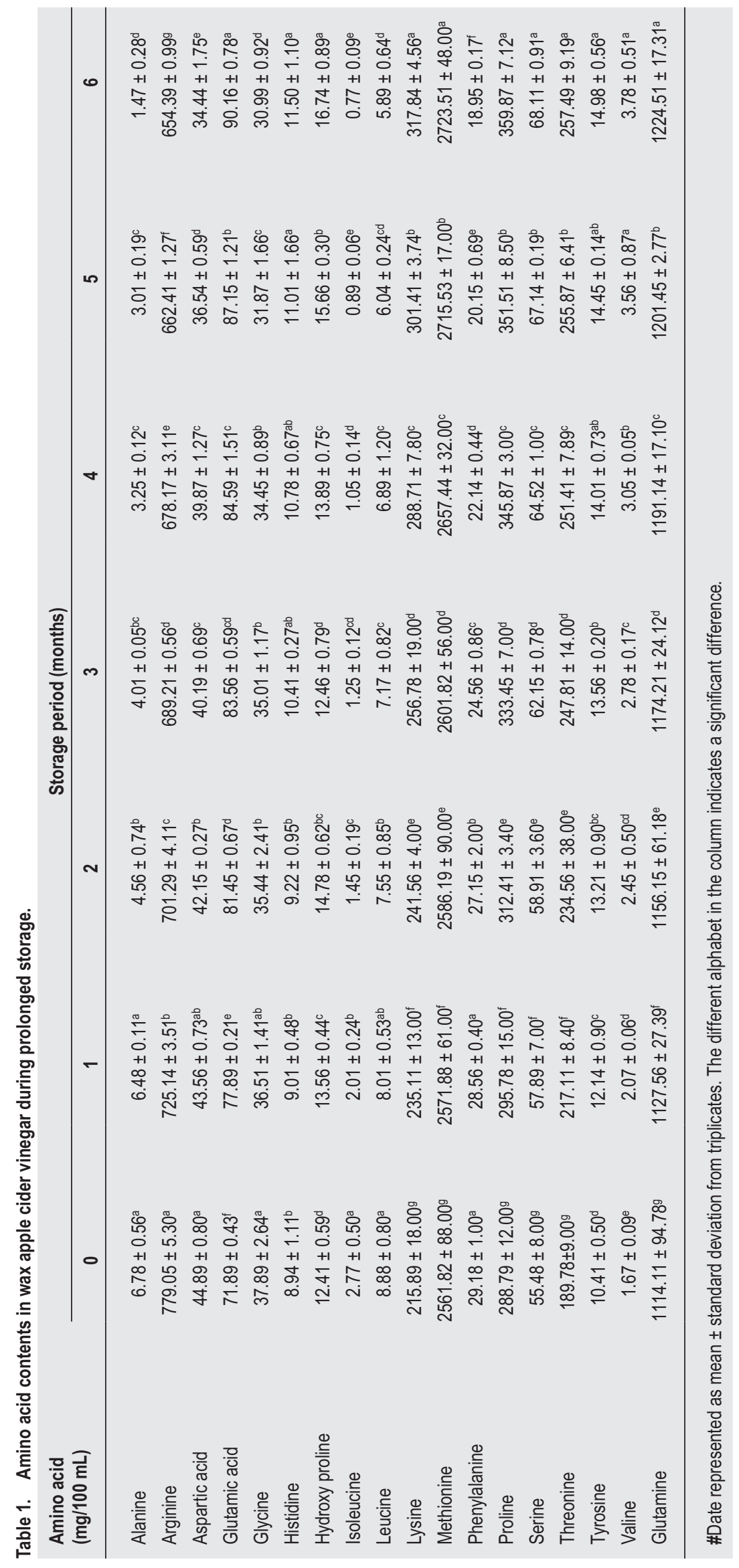




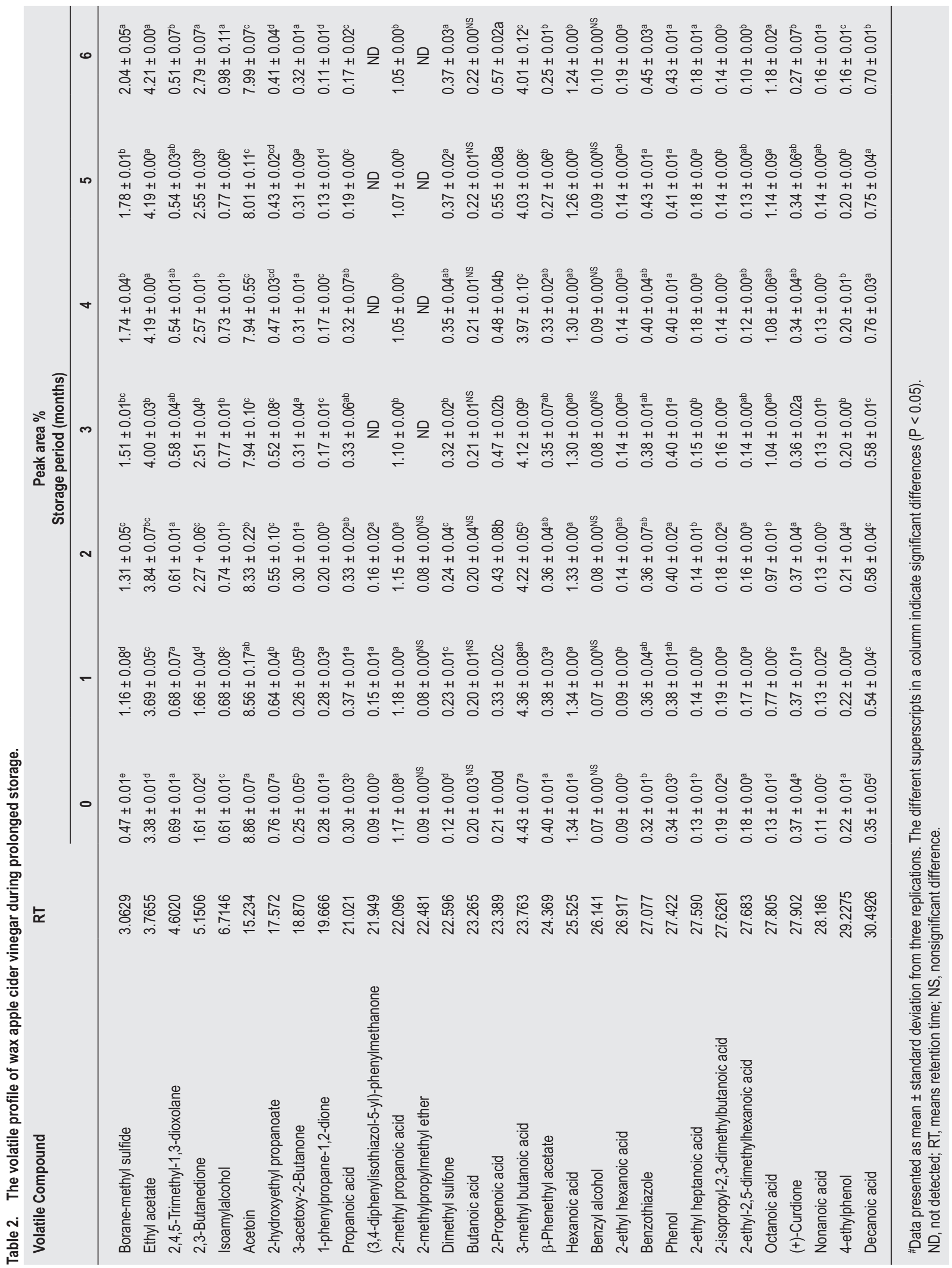


were nondetectable in WACV after two months of storage. Volatile compounds in the vinegar could be influenced by the environmental conditions, light intensity, constituents formed during vinegar production, and aging (Valero et al., 2005; Chen et al., 2020). RibéreauGayon et al. (2006) reported that oxygen plays a key role in the formation of volatile compounds in vinegar. Kang et al. (2020) observed that extended storage of fruit cider vinegar significantly decreased the alcoholic, bitterness, and sweetn flavors and significantly increased sourness and astringency flavors.

\section{Microbial growth}

Microbial growth in WACV was minimal to absent during the prolonged storage (Table 3). Total plate count showed active microbial growth in the samples at the beginning of the storage period, which could be because of the active stage of the acetic acid-producing bacteria. However, during the prolonged storage, the bacterial growth in WACV decreased because of acidity and the anaerobic conditions. Furthermore, pathogenic bacteria, particularly E. coli, were absent in the WACV throughout the storage. Similarly, yeast and mold also did not survive in the WACV. The results showed that WACV potently inhibited microbial growth. Yagnik et al. (2018) reported that cider vinegar could possess multiple antimicrobial properties against various microbial species, especially E. coli, Staphylococcus aureus, and Candida albicans, controlling the microbial growth and suppressing mononuclear cytokine and phagocytic responses. GomezGarcia et al. (2019) observed various organic acids and their antifungal effects. Their study reported that acetic acid inhibited (45.21\%) fungal growth compared with other organic acids. Yang et al. (2016) observed that phenolics and flavonoids from vinegar exhibited higher antimicrobial activity, especially against pathogens.

Table 3. Microbial growth in wax apple cider vinegar during prolonged storage.

\begin{tabular}{lccc}
$\begin{array}{l}\text { Storage } \\
\text { time } \\
\text { (months) }\end{array}$ & $\begin{array}{c}\text { Total plate } \\
\text { count } \\
(\log \text { CFU/mL) }\end{array}$ & $\begin{array}{c}\text { Yeast and mold } \\
(\log \text { CFU/mL) }\end{array}$ & $\begin{array}{c}\text { E. coli } \\
\text { (log CFU/mL) }\end{array}$ \\
\hline 0 & $2.4 \pm 0.3^{\mathrm{a}}$ & $\mathrm{ND}$ & $\mathrm{ND}$ \\
1 & $2.3 \pm 0.3^{\mathrm{a}}$ & $\mathrm{ND}$ & $\mathrm{ND}$ \\
2 & $1.8 \pm 0.0^{\mathrm{b}}$ & $\mathrm{ND}$ & $\mathrm{ND}$ \\
3 & $<10^{\mathrm{c}}$ & $\mathrm{ND}$ & $\mathrm{ND}$ \\
4 & $<10^{\mathrm{c}}$ & $\mathrm{ND}$ & $\mathrm{ND}$ \\
5 & $<10^{\mathrm{c}}$ & $\mathrm{ND}$ & $\mathrm{ND}$ \\
6 & $\mathrm{ND}$ & $\mathrm{ND}$ & $\mathrm{ND}$ \\
\hline
\end{tabular}

$\mathrm{ND}$, not detected.

\#Data presented as mean \pm standard deviation from three replications. The different superscripts in a column indicate significant differences.

\section{Conclusion}

This study was the first to understand the physiochemical characteristics, flavor, and functional properties of wax apple cider vinegar during prolonged storage. Overall, the study found that the storage period or aging of WACV significantly influenced its qualities. Organic acids, polyphenolics, and flavonoids in WACV increased significantly, and consequently, the antioxidant and antimicrobial activities were higher in the WACV. The flavor profile of WACV was significantly influenced by continuous changes in the amino acid contents during storage.

\section{Author contributions}

Lekjing $\mathrm{S}$ conducted the experiment, performed a literature review, and complied the first draft. Venkatachalam $\mathrm{K}$ developed the experimental design, conducted the experiments, reviewed, revised the manuscript, and performed the final revision. All authors agreed to publish this manuscript.

\section{Acknowledgments}

The authors acknowledge the Food Innovation and Product Development (FIPD) Laboratory for providing laboratory space and equipment support. Furthermore, the authors thank Associate Professor Dr. Seppo Karrila for proofreading the draft manuscript.

\section{Conflicts of interest}

No potential conflict of interest was reported by the authors.

\section{Funding}

The study received research grants from the Research and Development Office (RDO), Prince of Songkla University, Hatyai Campus, and Surat Thani Campus (project grant no. SIT590720S).

\section{References}

Alberti, A., Santos, T.P.M., Zielinski, A.A.F., Santos, C.M.E., Braga, C.M. and Demiate, I.M. 2016. Impact on chemical profile in apple juice and cider made from unripe, ripe and senescent dessert varieties. LWT-Food. Sci. Technol. 65:436-443. https:// doi.org/10.1016/j.lwt.2015.08.045

Alberti, A., Zielinski, A.A.F., Zardo, D.M., Demiate, I.M., Nogueira, A. and Mafra, L.I. 2014. Optimisation of the 
extraction of phenolic compounds from apples using response surface methodology. Food. Chem. 149:151-158. https://doi. org/10.1016/j.foodchem.2013.10.086

American Public Health Association. 1978. Standard methods for the examination of dairy products. 14th ed. APHA Inc., Washington, DC.

AOAC. 2000. Official methods of analysis. 15th ed. Association of Official Analytical Chemists, Washington, DC.

AOAC. 2002. Official methods of analysis. 16th ed. Association of Official Analytical Chemists, Washington, DC.

Ardö, Y. 2006. Flavour formation by amino acid catabolism. Biotechnol. Adv. 24(2): 238-242. https://doi.org/10.1016/j. biotechadv.2005.11.005

Bavishetty, S.C.B. and Venkatachalam, K. 2021. Physicochemical qualities and antioxidant properties of juice extracted from ripe and overripe wax apple as affected by pasteurization and sonication. J. Food. Process. Preserv. 45(6): e15524. https://doi. org/10.1111/jfpp.15524

Brand-Williams, W., Cuvelier, M.E. and Berset, C. 1995. Use of a free radical method to evaluate antioxidant activity. LWTFood. Sci. Technol. 28(1): 25-30. https://doi.org/10.1016/ S0023-6438(95)80008-5

Beever, R.E. and Bollard, E.G. 1970. The nature of the stimulation of fungal growth by potato extract. J. Gen. Microbiol. 60(2): 273279. https://doi.org/10.1099/00221287-60-2-273

Budak, H.N., Aykin, E., Seydim, C.A., Greene, K.A. and GuzelSeydim, B.Z. 2014. Functional properties of vinegar. J. Food. Sci. 79(5): 757-764. https://doi.org/10.1111/1750-3841.12434

Campodonico, P., Barbieri, E., Pizarro, M., Sotomayor, C.P. and Lissi, E.A. 1998. A comparison between total phenol content of wines and their TRAP values measured by the bleaching of ABTS radical cations. J. Chil. Chem. Soc. 43:281-285.

Charles, M., Martin, B., Ginies, C., Etievant, P., Coste, G. and Guichard, E. 2000. Potent aroma compounds of two red wine vinegars. J. Agric. Food. Chem. 48(1):70-77. https://doi. org/10.1021/jf9905424.

Chen, G., Zheng, F., Shui-Bing Lao, B.L., He, J., Huang, Z., Zeng, Y., et al. 2020. Phenolic and volatile compounds in the production of sugarcane vinegar. ACS. Omega. 5:30587-30535. https://doi. org/10.1021/acsomega.0c04524

Chidi, S.B., Bauer, F.F. and Rossouw, D. 2018. Organic acid metabolism and the impact of fermentation practices on wine acidity: a review. South African J. Enol. Vitic. 39(2): 1-15. https://doi. org/10.21548/39-2-3172

Dabija, A. and Hatnean, A.C. 2014. Study concerning the quality of apple vinegar obtained through classical method. J. Agroaliment. Proc. Technol. 20(4):304-310.

Davies, V.C., Gerard, M.L., Ferreyra, M.M., Schvab, C.M. and Solda, A.C. 2017. Bioactive compounds and antioxidant activity analysis during orange vinegar production. Food. Sci. Technol. 37(3):449-455. https://doi.org/10.1590/1678-457x.20816

Dias, R.D., Silva, S.M., Souza, C.A., Magalhaes-Guedes, T.K., Rezende Ribeiro, S.F. and Schwan, F.R. 2016. Vinegar production from Jabuticaba (Myriciaria jaboticaba) fruit using immobilized acetic acid bacteria. Food. Technol. Biotechnol. 54(3):351-359. https://doi.org/10.17113/ftb.54.03.16.44.16
Gomez-Garcia, M., Sol, C., de Nova, P.J.G., Puyalto, M., Mesas, L., Puente, H., et al. 2019. Antimicrobial activity of a selection of organic acids, their salts and essential oils against swine enteropathogenic bacteria. Porc. Health. Manag. 5(32):1-8. https://doi. org/10.1186/s40813-019-0139-4

Halliwell, B., Gutteridge, JMC and Aruoma, O.I. 1987. The deoxyribose method: a simple "test-tube" assay for determination of rate constants for reactions of hydroxyl radicals. Anal. Biochem. 165:215-219. https://doi.org/10.1016/0003-2697(87)90222-3

Hornedo-Ortega, R., Alvarez-Fernandez, M.A., Cerezo, A.B., Garcia-Garcia, I., Troncoso, A.M. and Garcia-Parrilla, M.C. 2017. Influence of fermentation process on the anthocyanin composition of wine and vinegar elaborated from strawberry. J. Food. Sci. 82(2):364-372. https://doi.org/10.1111/1750-3841. 13624

Ho, W.C., Lazim, M.A., Fazry, S., Zaki, H.H.K.U. and Lim, S. 2017. Varieties, production, composition and health benefits of vinegars: a review. Food. Chem. 221:1621-1630. https://doi. org/10.1016/j.foodchem.2016.10.128

Jackson, R.S. 2008. Biochemistry of alcoholic fermentation. In: Wine science, principles and applications. Academic Press, San Diego, USA, pp. 358-363.

Johnston, C.S. and Gaas, C.A. 2006. Vinegar: medicinal uses and antiglycemic effect. Med. Gen. Med. 8(2):61.

Joshi, V.K., Yadav, J., Sharma, R., Joshi, D. and Gupta, R.K. 2016. Effect of nutrients and growth stimulators on acetic acid fermentation using natural consortia. Int. J. Food. Ferment. Technol. 6: 81-95. https://doi.org/10.5958/2277-9396.2016.00030.1

Kabasakalis, V., Siopidou, D. and Moshatou, E. 2000. Ascorbic acid content of commercial fruit juices and its rate of loss upon storage. Food. Chem. 70(3):325-328. https://doi.org/10.1016/ S0308-8146(00)00093-5

Kang, M., Ha, J. and Lee, Y. 2020. Physiochemical properties, antioxidant activities and sensory characteristics of commercial grape vinegars during long term storage. Food. Sci. Technol. (Campinas). 40(4):909-916. https://doi.org/10.1590/fst.25119

Kaur, P., Kocher, G.S. and Phutela, R.P. 2011. Production of tea vinegar by batch and semicontinuous fermentation. J. Food. Sci. Technol. 48(6):755-758. https://doi.org/10.1007/ s13197-010-0143-9

Kocher, G.S., Kalra, K.L. and Phutela, R.P. 2006. Comparative production of sugarcane vinegar by different immobilization techniques. J. Inst. Brew. 112:264-266. https://doi.org/10.1002/j.2050-0416.2006. tb00722.x

Lea, A.G.H. 1989. Cider vinegar. In: Downing, D.L. (ed.), ,Processed apple products. Van Nostrand Reinhold, New York, pp. 279301. https://doi.org/10.1007/978-1-4684-8225-6_13

Lee, K.K., Oh, C.Y., Cho, K.W. and Ma, Y.J. 2015. Antioxidant and anti-inflammatory activity determination of one hundred kinds of pure chemical compounds using offline and online screening HPLC assay. eCAM. 165457:1-13. https://doi. org $/ 10.1155 / 2015 / 165457$

Mas, A., Torija, J.M., Garcia-Parrilla, C.M. and Troncoso, M.A. 2014. Acetic acid bacteria and the production and quality of wine vinegar. Sci. World. J. 394671:1-6. https://doi.org/10.1155/ 2014/394671 
Moruno, G.E., Delfini, C., Pessione, E. and Giunta, C. 1993. Factors affecting acetic acid production by yeasts in strongly clarified grape musts. Microbios. 74: 249-256.

Pietrowski, G.A.M., Santos, C.M., Sauer, E., Wosiacki, G. and Nogueira, A. 2012. Influence of fermentation with Hanseniaspora sp. yeast on the volatile profile of fermented apple. J. Agric. Food. Chem. 60:9815-9821. https://doi. org/10.1021/jf302290k

Raspor, P. and Goranovic, D. 2008. Biotechnological applications of acetic acid bacteria. Crit. Rev. Biotechnol. 28(2):101-124. https://doi.org/10.1080/07388550802046749

Ribéreau-Gayon, P., Glories, Y., Maujean, A. and Dubordieu, D. 2006. Handbook of enology: the Chemistry of Wine Stabilization and Treatments. Wiley, New York. https://doi. org/10.1002/0470010398

Schlesier, K., Harwat, M., Bohm. V. and Bitsch, R. 2002. Assessment of antioxidant, activity by using different in vitro methods. Free. Radic. Res. 36(2):1-10. https://doi. org/10.1080/10715760290006411

Shimoji, Y., Tamura, Y., Nakamura, Y., Nanda, K., Nishidai, S., Nishikawa, Y., et al. 2002. Isolation and identification of DPPH radical scavenging compounds in Kurosu (Japanese unpolished rice vinegar). J. Agric. Food. Chem. 50(22):6501-6503. https:// doi.org/10.1021/jf020458f

Štornik, A., Skok, B. and Trcek, J. 2016. Comparison of cultivable acetic acid bacterial microbiota in organic and conventional apple cider vinegar. Food. Technol. Biotechnol. 54:113-119. https://doi.org/10.17113/ftb.54.01.16.4082

Tarazona-Diaz, M.P. and Aguayo, E. 2013. Influence of acidification, pasteurization, centrifugation and storage time and temperature on watermelon juice quality. J. Sci. Food. Agric. 93(15):38633869. https://doi.org/10.1002/jsfa.6332

Techakanon, C. and Sirimuangmoon, C. 2020. The effect of pasteurization and shelf life on the physicochemical, microbiological, antioxidant and sensory properties of rose apple cider during cold storage. Beverages. 6:43. https://doi.org/10.3390/ beverages6030043

Techakanon, C. and Venkatachalam, K. 2021. The effect of pasteurization conditions and storage time on microbial safety, quality and antioxidant properties of cider from rose apple (Syzygium agueum Alston cv. Taaptimjan). Chiang. Mai. Uni. J. Nat. Sci. 20(2): e2021034. https://doi.org/10.12982/CMUJNS.2021.034.

Ubeda, C., Callejoin, R.M., Hidalgo, C., Torija, M.J., Mas, A., Troncoso, A.M. et al. 2011. Determination of major volatile compounds during the production of fruit vinegar by static headspace gas chromatography-mass spectrometry method. Food. Res. Int. 44(1): 259-268. https://doi.org/10.1016/j. foodres.2010.10.025

Valero, E., Berlanga, M.T., Roldan, M.P., Jimenez, C., Garcia, I. and Mauricio, C.J. 2005. Free amino acids and volatile compounds in vinegars obtained from different types of substrate. J. Sci. Food Agric. 85(4): 603-608. https://doi.org/10.1002/jsfa.2016

Venkatachalam, K., Techankanon, C. and Thitithanakul, S. 2018. Impact of ripening stage of wax apples on chemical profiles of juice and cider. ACS. Omega. 3:6710-6718. https://doi. org/10.1021/acsomega.8b00680

Verzelloni, E., Tagliazucchi, D. and Conte, A. 2007. Relationship between the antioxidant properties and the phenolic and flavonoid content in traditional balsamic vinegar. Food. Chem. 105(2): 564-571. https://doi.org/10.1016/j.foodchem.2007.04.014

Vithlani, V.A. and Patel, H.V. 2010. Production of functional vinegar from Indian jujube (Zizyphus mauritiana) and its antioxidant properties. J. Food. Technol. 8(3): 143-149. https://doi. org/10.3923/jftech.2010.143.149

Wang, B., Shao, Y., Chen, T., Chen, W. and Chen, F. 2015. Global insights into acetic acid resistance mechanisms and genetic stability of Acetobacter pasteurianus strains by comparative genomics. Sci. Rep. 5:18330-18330. https://doi.org/10.1038/ srep 18330

Wood, D. and Anderson, K. 2006. What determines the future value of an icon wine? New evidence from Australia. J. Wine. Econ. 1(2):141-161. https://doi.org/10.1017/S1931436100000171

Yagnik, D., Serafin, V. and Shah, J.A. 2018. Antimicrobial activity of apple cider vinegar against Escherichia coli, Staphylococcus aureus and Candida albicans; downregulating cytokine and microbial protein expression. Sci. Rep. 8:1732. https://doi. org/10.1038/s41598-017-18618-x

Yang, J.F., Yang, C.H., Liang, M.T., Gao, Z.J., Wu, Y.W. and Chuang, L.Y. 2016. Chemical composition, antioxidant, and antibacterial activity of wood vinegar from Litchi chinensis. Molecules. 21(9):1-10. https://doi.org/10.3390/molecules21091150

Zhao, C., Xia, T., Du, P., Duan, W., Zhang, B., Zhang, J. et al. 2018. Chemical composition and antioxidant characteristic of traditional and industrial Zhenjiang aromatic vinegars during the aging process. Molcules. 23(11): 2949. https://doi.org/10.3390/ molecules23112949 